\title{
Controle Químico do AgUAPÉ (Eichhornia crassipes)
}

\author{
Chemical Control of Waterhyacinth (Eichhornia crassipes)
}

NEVES, T. ${ }^{2}$, FOLONI, L.L. ${ }^{3}$ e PITELLI, R.A. ${ }^{4}$

\begin{abstract}
RESUMO - Foram testados os produtos 2,4-D, sulfentrazone, glyphosate, diquat, imazapyr, imazapic, metsulfuron-metil e sulfosate. Conduziram-se seis ensaios em condições controladas de casa de vegetação, visando estudar a eficácia no controle de Eichhornia crassipes (Mart.) Solms. Em todos os ensaios, as plantas de aguapé foram cultivadas em caixas com substrato como material de fundo e água completando o volume; os herbicidas foram aplicados com pulverizador costal a $\mathrm{CO}_{2}$ No primeiro ensaio, foram testados os herbicidas diquat, glyphosate, imazapyr e sulfentrazone. O diquat e o glyphosate foram altamente eficazes no controle de E. crassipes, com ação mais rápida do primeiro produto. Imazapyr e sulfentrazone indicaram que maior intensidade de controle poderá ser obtida em maior tempo de observação. No segundo ensaio, foram testados diquat, glyphosate, imazapyr, imazapic, 2,4-D, metsulfuronmetil e sulfosate. Diquat, glyphosate, imazapyr e 2,4-D foram eficazes no controle do aguapé. Diquat e 2,4-D mostraram ação mais rápida. O imazapyr apresentou lenta evolução, e o glyphosate, ação intermediária. Os herbicidas imazapic, sulfosate e metsulfuron, em função do tempo de avaliação, não mostraram eficácia satisfatória. No terceiro ensaio, foram estudados imazapyr e glyphosate aplicados três, seis e nove horas antes da incidência de chuva simulada. O glyphosate apresentou maior eficácia que o imazapyr e o glyphosate não sofreu influência do intervalo entre a aplicação e a ocorrência de chuva. No entanto, o desenvolvimento inicial dos sintomas foi mais rápido em intervalos maiores. No quarto ensaio foi estudado o diquat, aplicado nos períodos noturno e diurno, o qual foi eficiente no controle do aguapé na dose de $1,0 \mathrm{~L} \mathrm{ha}^{-1}$ ou acima. Aplicações noturnas apenas proporcionaram ação mais rápida do produto, não influenciando o controle final. No quinto ensaio foi estudado o diquat em aplicações diurnas ou noturnas e em intervalos de 30, 60 e 120 minutos entre a aplicação e a ocorrência de chuva simulada, tendo ele mostrado elevada atividade herbicida contra o aguapé, com eficácia maior na dose de 2,00 L ha-1. A ação do produto foi maior em aplicações noturnas, período em que houve maior importância da extensão do intervalo entre a aplicação do produto e a ocorrência da primeira chuva. O último ensaio foi realizado em campo, para estudo da ação do imazapyr aplicado sobre plantas de aguapé crescidas em caixas de cimento-amianto. Todas as doses estudadas proporcionaram controle total da planta daninha. As doses mais elevadas apresentaram efeitos mais rápidos.
\end{abstract}

Palavras-chave: herbicida, planta aquática, planta daninha.

\begin{abstract}
ABSRACT - Six assays were carried out under greenhouse conditions to study the efficacy of diquat, glyphosate, sulfosate, imazapyr, 2,4-D, metsulfuron-methyl, sulfentrazone and imazapic in controlling Eichhornia crassipes (Mart.) Solms. The same $\mathrm{CO}_{2}$ pressurized sprayer was used in all assays. Diquat, glyphosate, imazapyr and sulfentrazone were studied in the first assay. Diquat and glyphosate were highly efficient in controlling $\boldsymbol{E}$. crassipes. The symptoms developed faster in diquat-treated plants. The symptoms promoted by imazapyr and sulfentrazone were progressive all over the experimental period, suggesting that higher control intensity could be achieved obtained during a longer observation time. Waterhyacinth control was studied in the second assay, using diquat, glyphosate, imazapyr, imazapic, 2,4-D, metsulfuron-methyl, and sulphosate. Diquat, glyphosate, imazapyr and 2,4-D showed good control of waterhyacinth
\end{abstract}

Recebido para publicação em 10/12/2001 e na forma revisada em 28/1/2002.

2 Eng.-Agr., FCAVJ-UNESP, 148070-00 Jaboticabal-SP. ${ }^{3}$ Eng.-Agr, Dr., Prof. Colab. FEAGRI-UNICAMP, Caixa Postal 6011, 13083-970 Campinas-SP, ${ }^{4}$ Eng.-Agr., Dr. Prof. Titular do DDAA-FCAVJ-UNESP, 148070-00 Jaboticabal-SP. 
The control promoted by diquat and 2,4-D showed quick results. Imazapyr showed slow control action. Under the experimental conditions, imazapic, sulfosate and metsulfuron-methyl did not show good control of this aquatic weed. Waterhyacinth control promoted by imazapyr and glyphosate sprayed at 3, 6, and 9 hours before simulated rain were studied. Glyphosate was more efficient in controlling $\boldsymbol{E}$. crassipes than imazapyr. For glyphosate, the interval between spraying and rain did not affect the final control (thirty days after spraying), but the development of the symptom was faster at higher doses. In the fourth assay, waterhyacinth control was studied using diquat sprayed during the day or at night. The herbicide was efficient in controlling waterhyacinth at 1,O L ha $\mathrm{L}^{-1}$ or higher. Night spraying showed faster symptoms than day-spraying, but the symptons were similar in the final control. In the fifth assay, diquat's waterhyacinth control efficacy was studied. It was sprayed during the day or night, at intervals of 30, 60 and 120 minutes between spraying and simulated rain. Diquat was very efficient in controlling waterhyacinth, mainly at 2,00 $\mathrm{L} \mathrm{ha}^{-1}$. Herbicide action was stronger during night spraying when broader intervals occurred between spraying and the first rain. A last assay was carried out under field conditions, to study waterhyacinth control by imazapyr sprayed on E. crassipes grown in small ponds. All the doses promoted a good waterhyacinth control. The effects were faster at higher doses.

Key words: herbicide, aquatic plant, weed.

\section{INTRODUÇÃO}

As macrófitas aquáticas, além de seu papel fundamental no estoque de energia e carbono nas bases das pirâmides alimentares, promovem habitats adequados para muitos organismos e servem de suporte à oviposição e refúgio de muitos peixes e outros animais.

Contudo, o crescente desenvolvimento tecnológico do homem promoveu sério desequilíbrio nos ambientes aquáticos, como a alteração de ambientes lóticos em lênticos, a retirada da proteção e da competição proporcionada pelas matas ciliares, a erosão de solos agrícolas e o despejo de resíduos industriais e urbanos que se acumulam nos rios e lagos, alterando o equilíbrio físico-químico desses meios. Ao receber uma descarga de resíduos, começa, nos rios e lagos, o processo de autodepuração realizado pelos organismos, que transformam o material biodegradável em nutrientes, promovendo, freqüentemente, a eutrofização do sistema. Todos esses fatores contribuem para o crescimento intenso de certos vegetais aquáticos, desde algas até macrófitas, que acabam por infestar vastas áreas da superfície livre dos corpos d'água, influenciando significativamente seus múltiplos usos.

Algumas espécies oriundas de outras regiões podem ter suas expansões aumentadas por não encontrarem inimigos naturais ou predadores eficazes no novo habitat, sendo um bom exemplo o aguapé [Eichhornia crassipes (Mart.) Solms]. Desse modo, o controle químico surge como uma opção econômica e eficaz para o controle dessas plantas.

Vários trabalhos realizados por diferentes pesquisadores têm comprovado a eficiência do controle químico e a sua segurança sobre organismos aquáticos através do uso de diversos herbicidas: 2,4 D (Joyle \& Sikka, 1977; Selvan \& Lall, 1981; Martins et al., 1999), glyphosate (Van et al., 1987; Martins et al., 1999), diquat (Martins et al., 1999) e imazapyr (Martins et al, 1999). No entanto, no Brasil, onde não existem herbicidas registrados comercialmente para plantas aquáticas, poucas informações podem ser obtidas para o controle desta planta daninha aquática, como as de Martins et al. (1999).

Nesse contexto, o presente trabalho de pesquisa teve por objetivo estudar o controle químico do aguapé, realizando vários testes de eficácia com herbicidas disponiveis no mercado, e, também, os fatores que pudessem interferir nessas aplicações, como horário de aplicação e ocorrência de chuva.

\section{MATERIAL E MÉTODOS}

Os experimentos foram realizados no Departamento de Biologia Aplicada à Agropecuária da Faculdade de Ciências Agrárias e Veterinárias, UNESP, campus de 
Jaboticabal. O município está localizado na região Centro-Norte do Estado de São Paulo $\left(21^{\circ} 15^{\prime} 22^{\prime \prime}\right.$ de latitude sul e $48^{\circ} 18^{\prime} 58^{\prime \prime}$ de longitude oeste, com altitude média de $575 \mathrm{~m}$ ). O clima é do tipo Cwa, de Köeppen, sendo um clima subtropical úmido, com estiagem no inverno.

Em todos os experimentos, o sedimento de fundo das caixas de cultivo do aguapé foi constituído de uma mistura de solo com $60 \%$ do substrato comercial Plantmax e $40 \%$ de terra adubada com superfosfato simples, cloreto de potássio e sulfato de amônio em quantidades suficientes para que o sedimento atingisse 300 , 200 e 150 ppm de P, K e N, respectivamente.

Nos cinco primeiros experimentos foram utilizadas caixas plásticas com capacidade para 3,75 litros, com dimensões de $15 \mathrm{~cm}$ de comprimento, $15 \mathrm{~cm}$ de largura e $15 \mathrm{~cm}$ de profundidade. Em cada caixa foram colocados $4 \mathrm{~cm}$ de substrato, completados com água até atingir altura de $8 \mathrm{~cm}$.

No sexto experimento foram utilizadas caixas de cimento-amianto com capacidade para 90 litros, com dimensões de $60 \mathrm{~cm}$ de comprimento, $60 \mathrm{~cm}$ de largura e $25 \mathrm{~cm}$ de profundidade. Em cada caixa foram colocados $15 \mathrm{~cm}$ de substrato, completados com água até atingir altura de $20 \mathrm{~cm}$.

Todos os experimentos foram instalados no delineamento experimental inteiramente casualizado; o sexto experimento teve seis repetições, o segundo, quatro, e os demais foram conduzidos com três repetições.

Para a análise estatística das médias de notas de controle foram usados: análise de variância, teste de Tukey para comparação de médias, contrastes ortogonais e desdobramento de graus de liberdade.

O critério de avaliação foi a estimativa visual da porcentagem de material vegetal que se encontrava necrosado e morto acima da lâmina de água, a qual foi considerada como ação de controle do herbicida.

No primeiro experimento foram testadas as doses de 1,0;2,0;3,0; 4,0; 5,0;6,0; 7,0; e 8,0 de diquat (solução aquosa concentrada a $200 \mathrm{~g} \mathrm{ha}^{-1}$ ); 3,0 e 6,0 de glyphosate (grânulos autodispersiveis a $720 \mathrm{~g} \mathrm{ha}^{-1}$ ); 2,0 e $4,0 \mathrm{de}$ imazapyr (concentrado solúvel a $250 \mathrm{~g} \mathrm{ha}^{-1}$ ) e
1,6 de sulfentrazone (suspensão concentrada a $500 \mathrm{~g} \mathrm{ha}^{-1}$ ), todos em $\mathrm{L} \mathrm{ha}{ }^{-1}$ do produto comercial, e uma testemunha, no controle do aguapé cultivado em caixas pequenas. Rebentos isolados de aguapé foram plantados no dia 8 de fevereiro, com aplicação em 6 de março de 1998, entre 14 h30 e 15h10. A aplicação foi realizada com pulverizador costal à pressão constante $\left(\mathrm{CO}_{2}\right)$, munido de barra com quatro bicos XR 110.02 e regulado para um gasto de volume de calda de $200 \mathrm{~L} \mathrm{ha}^{-1}$, equipamento utilizado nas mesmas condições para os demais experimentos. As condições de aplicação foram: temperatura do ar (tar) de $32,0{ }^{\circ} \mathrm{C}$, temperatura da água (ta) de $26,4{ }^{\circ} \mathrm{C}$, umidade relativa do ar (UR) de 53\%, cobertura do céu (CC) de 30\% e ventos fracos.

No segundo experimento, foram testadas as doses de 2,5; 3,75; e 5,0 $\mathrm{L} \mathrm{ha}^{-1}$ de diquat; $5,0,6,0$ e 7,0 kg ha-1 de glyphosate; 4,0, 5,0 e 6,0 $\mathrm{L} \mathrm{ha}^{-1}$ de imazapyr; 2,0 e 4,0 L ha-1 de 2,4-D (concentrado solúvel a $670 \mathrm{~g} \mathrm{ha}^{-1}$ ), $0,1 \mathrm{e}$ $0,2 \mathrm{~kg} \mathrm{ha}^{-1}$ de imazapic (grânulos autodispersiveis a $700 \mathrm{~g} \mathrm{ha}^{-1}$ ); 2,0, 4,0 e 6,0 $\mathrm{g} \mathrm{ha}^{-1} \mathrm{de}$ metsulfuron-metil (grânulos autodispersíveis a $600 \mathrm{~g} \mathrm{ha}^{-1}$ ); e 2,0 e 3,0 $\mathrm{L} \mathrm{ha}^{-1}$ de sulfosate (concentrado solúvel a $480 \mathrm{~g} \mathrm{ha}^{-1}$ ), sendo as doses expressas em produto comercial, e uma testemunha. Os rebentos foram plantados no dia 19 de março e a aplicação foi efetuada em 13 de abril de 1998 , entre $16 \mathrm{~h} 45$ e $17 \mathrm{~h} 30$. As condições de aplicação foram: tar $-24,0{ }^{\circ} \mathrm{C}$, ta - 26, $6^{\circ} \mathrm{C}$, UR - $60 \%$, cobertura do céu - 80\% e ventos fracos.

No terceiro experimento foi estudado o controle do aguapé pelas doses de 5,0 e 6,0 kg ha ${ }^{-1}$ de glyphosate e 4,0 e 6,0 $\mathrm{L} \mathrm{ha}^{-1} \mathrm{de}$ imazapyr e uma testemunha com incidência de chuva simulada de $6,92 \mathrm{~mm}$ durante 10 minutos, nos intervalos de três, seis e nove horas após a aplicação dos tratamentos em aguapé cultivado em caixas pequenas. Rebentos de aguapé foram plantados no dia 20 de abril e a aplicação foi efetuada no dia 16 de maio de 1998, entre $11 \mathrm{~h} 30$ e $12 \mathrm{~h} 10$, com tar de $23,0{ }^{\circ} \mathrm{C}$, ta de $22,5{ }^{\circ} \mathrm{C}$, UR de $81 \%$, CC de $85 \%$ e ventos fracos.

No quarto experimento foi estudado o controle do aguapé pelas doses de 0,$5 ; 1,0 ; 2,0$; e 3,0 $\mathrm{L} \mathrm{ha}^{-1}$ de diquat e uma testemunha aplicadas nos períodos diurno e noturno. Os rebentos de aguapé foram plantados no dia 22 
de maio e a aplicação efetuada no dia 3 de junho, entre $12 \mathrm{~h} 15$ e $12 \mathrm{~h} 40$ (aplicação diurna) e $23 \mathrm{~h} 5$ e $23 \mathrm{~h} 40$ (aplicação noturna). Na aplicação diurna, as condições foram de tar $25,0{ }^{\circ} \mathrm{C}$, ta $-19,0{ }^{\circ} \mathrm{C}$, UR $-65 \%, \mathrm{CC}-80 \%$ e ventos fracos; e para aplicação noturna: tar $15,0{ }^{\circ} \mathrm{C}$, ta $-13,0 \stackrel{\circ}{ } \mathrm{C}, \mathrm{UR}-100 \%$ e ventos fracos.

No quinto experimento foi estudado o controle do aguapé com as doses de 1,0 e 2,0 $\mathrm{L} \mathrm{ha}^{-1}$ de diquat e testemunha, aplicadas nos períodos diurno e noturno, em intervalos de 30, 60 e 120 minutos entre a aplicação e a chuva simulada de $6,92 \mathrm{~mm}$ em dez minutos. O aguapé foi plantado em dia 29 de maio e a aplicação foi feita no dia 17 de junho de 1998, entre $12 \mathrm{~h} 15$ e $12 \mathrm{~h} 30$ (aplicação diurna) e $23 \mathrm{~h} 20$ e 23h40 (aplicação noturna). Na aplicação diurna, as condições foram: tar $-30,0{ }^{\circ} \mathrm{C}$, ta $-24,0{ }^{\circ} \mathrm{C}$, UR - 52\%, CC - 60\% e ventos fracos; e na aplicação noturna: tar $-14,0{ }^{\circ} \mathrm{C}$, ta $-12,0{ }^{\circ} \mathrm{C}$, UR $90 \%$ e ventos fracos.

No sexto experimento, foram testadas as doses de 1,0; 2,0; 3,0; 6,0; e 8,0 $\mathrm{L} \mathrm{ha}^{-1} \mathrm{de}$ imazapyr e uma testemunha no controle do aguapé cultivado. O aguapé foi plantado em 23 de setembro e a aplicação ocorreu em 24 de novembro de 1997 ( 8 h00 e $8 \mathrm{~h} 15$ ), com tar $32,0{ }^{\circ} \mathrm{C}$, ta $-24,5{ }^{\circ} \mathrm{C}$, UR $-59 \%$, CC $-70 \%$ e ausência de ventos.

\section{RESULTADOS E DISCUSSÃO}

\section{1 - Experimento - Estudo de diferentes doses de diquat, glyphosate, imazapyr e sulfentrazone}

Na Tabela 1 estão apresentados os resultados referentes às avaliações do controle de aguapé promovido pelos herbicidas diquat, glyphosate, imazapyr e sulfentrazone.

De maneira geral, no período de avaliação, o diquat e o glyphosate foram altamente eficazes no controle de E. crassipes, com ação mais rápida do primeiro produto. Os sintomas promovidos pelo imazapyr e sulfentrazone foram crescentes no período experimental, indicando que maior intensidade de controle poderá ser obtida em maior período de observação.

Tabela 1 - Notas de avaliação do controle de Eichhornia crassipes promovido por diferentes doses de diquat, glyphosate, imazapyr e sulfentrazone $\left(1,6 \mathrm{~L} \mathrm{ha}^{-1}\right)$, aos 3,11, 20 e 30 dias após a aplicação dos herbicidas

\begin{tabular}{|l|c|c|c|c|c|}
\hline \multirow{2}{*}{ Herbicida } & Dose (p.c.) $)^{\frac{1}{1}}$ & \multicolumn{4}{|c|}{ Avaliação (dias após aplicação ) } \\
\cline { 3 - 6 } & $\mathrm{L} \mathrm{ha}^{-1}$ & 3 & 11 & 20 & 30 \\
\hline diquat & 1,0 & $4,75 \mathrm{~b}$ & $9,00 \mathrm{a}$ & $9,00 \mathrm{a}$ & $9,00 \mathrm{a}$ \\
diquat t & 2,0 & $4,50 \mathrm{~b}$ & $9,00 \mathrm{a}$ & $9,00 \mathrm{a}$ & $9,00 \mathrm{a}$ \\
diquat & 3,0 & $5,75 \mathrm{ab}$ & $9,00 \mathrm{a}$ & $9,00 \mathrm{a}$ & $9,00 \mathrm{a}$ \\
diquat t & 4,0 & $6,75 \mathrm{a}$ & $9,00 \mathrm{a}$ & $9,00 \mathrm{a}$ & $9,00 \mathrm{a}$ \\
diquat & 5,0 & $6,50 \mathrm{a}$ & $9,00 \mathrm{a}$ & $9,00 \mathrm{a}$ & $9,00 \mathrm{a}$ \\
diquat t & 6,0 & $6,75 \mathrm{a}$ & $9,00 \mathrm{a}$ & $9,00 \mathrm{a}$ & $9,00 \mathrm{a}$ \\
diquat & 7,0 & $7,00 \mathrm{a}$ & $9,00 \mathrm{a}$ & $9,00 \mathrm{a}$ & $9,00 \mathrm{a}$ \\
diquat t & 8,0 & $6,50 \mathrm{a}$ & $9,00 \mathrm{a}$ & $9,00 \mathrm{a}$ & $9,00 \mathrm{a}$ \\
glyphosate & $3,0 \mathrm{~kg}$ & $1,00 \mathrm{c}$ & $3,75 \mathrm{bc}$ & $8,75 \mathrm{a}$ & $9,00 \mathrm{a}$ \\
glyphosate & $6,0 \mathrm{~kg}$ & $1,00 \mathrm{c}$ & $5,00 \mathrm{~b}$ & $9,00 \mathrm{a}$ & $9,00 \mathrm{a}$ \\
imazapyr & 2,0 & $1,00 \mathrm{c}$ & $2,00 \mathrm{de}$ & $5,00 \mathrm{c}$ & $6,25 \mathrm{c}$ \\
imazapyr & 4,0 & $1,00 \mathrm{c}$ & $2,50 \mathrm{~cd}$ & $6,75 \mathrm{~b}$ & $8,00 \mathrm{~b}$ \\
sulfentrazone & 1,6 & $1,00 \mathrm{c}$ & $4,00 \mathrm{~b}$ & $5,00 \mathrm{c}$ & $6,00 \mathrm{c}$ \\
testemunha & & $1,00 \mathrm{c}$ & $1,00 \mathrm{e}$ & $1,00 \mathrm{~d}$ & $1,00 \mathrm{~d}$ \\
\hline F tratamento & & $66,11 * *$ & $50,11^{* *}$ & $225,87 * *$ & $1.502,0 * *$ \\
CV (\%) & 5,58 & 9,68 & 3,88 & 1,46 \\
d.m.s. & & 0,30 & 0,41 & 0,21 & 0,08 \\
\hline
\end{tabular}

${ }^{1 /}$ produto comercial; $* *$ significativo a $1 \%$ de probabilidade.

Médias acompanhadas de mesma letra não diferem estatisticamente entre si. 


\section{$2^{\circ}$ experimento - Estudo de diferentes doses de diquat, glyphosate, imazapyr, 2,4-D, imazapic, metsulfuron-metil e sulfosate}

Na Tabela 2 encontram-se os resultados referentes às avaliações de controle do aguapé realizadas aos 3, 10, 20 e 30 dias após a aplicação dos herbicidas, acompanhado dos resultados da análise de variância e do teste de comparação de média (Tukey 5\%).

Pelos resultados obtidos, os herbicidas diquat, glyphosate, imazapyr e 2,4-D foram eficazes no controle do aguapé num período de observação de 30 dias, com pequena desvantagem para o imazapyr. Os herbicidas diquat e 2,4-D mostraram ação mais rápida, obtendo melhores valores de controle nas primeiras avaliações. O imazapyr mostrou lenta evolução dos sintomas de intoxicação, e o glyphosate teve velocidade de ação intermediária. Os herbicidas imazapic, sulfosate e metsulfuron, nas condições experimentais e de tempo de avaliação, não mostraram eficácia satisfatória para o controle desta planta daninha aquática.

\section{3o experimento - Diferentes doses de glyphosate e imazapyr, aplicadas em diferentes intervalos antes da ocorrência de chuva simulada}

Na Tabela 3 estão apresentados os resultados das avaliações de controle de aguapé proporcionado pela aplicação das doses de 5,00 e $6,00 \mathrm{~kg} \mathrm{ha}^{-1}$ de glyphosate e 4,00 e 6,00 $\mathrm{L} \mathrm{ha}^{-1}$ de imazapyr, com intervalos de três, seis e nove horas antes da incidência de chuva simulada de $6,92 \mathrm{~mm}$ em 10 minutos, estando incluídos os dados da análise de variância e do teste de comparação de média.

Tabela 2 - Notas médias de avaliação do controle de Eichhornia crassipes promovido por diferentes doses de diquat, glyphosate, imazapyr, imazapic, 2,4-D, metsulfuron e sulfosate aos 3, 10, 20 e 30 dias após a aplicação dos herbicidas

\begin{tabular}{|c|c|c|c|c|c|}
\hline \multirow{2}{*}{ Herbicida } & \multirow{2}{*}{$\begin{array}{c}\text { Dose (p.c. })^{1^{1 /}} \\
\mathrm{L} \mathrm{ha}^{-1}\end{array}$} & \multicolumn{4}{|c|}{ Avaliação (dias após a aplicação) } \\
\hline & & 3 & 10 & 20 & 30 \\
\hline diquat & 2,50 & $71,67 \mathrm{c}$ & $81,67 \mathrm{ab}$ & $95,00 \mathrm{ab}$ & $96,67 \mathrm{a}$ \\
\hline diquat & 3,75 & $83,33 \mathrm{ab}$ & $83,33 \mathrm{a}$ & $90,00 \mathrm{abc}$ & $96,67 \mathrm{a}$ \\
\hline diquat $\mathrm{t}$ & 5,00 & $88,33 \mathrm{a}$ & $90,00 \mathrm{a}$ & $100,00 \mathrm{a}$ & $100,00 \mathrm{a}$ \\
\hline glyphosate & $5,00 \mathrm{~kg}$ & $15,00 \mathrm{fg}$ & $60,00 \mathrm{c}$ & $85,00 \mathrm{abcd}$ & $95,00 \mathrm{ab}$ \\
\hline glyphosate & $6,00 \mathrm{~kg}$ & $15,00 \mathrm{fg}$ & $66,67 \mathrm{bc}$ & $100,00 \mathrm{a}$ & $100,00 \mathrm{a}$ \\
\hline glyphosate & $7,00 \mathrm{~kg}$ & $15,00 \mathrm{fg}$ & $80,00 \mathrm{ab}$ & $100,00 \mathrm{a}$ & $100,00 \mathrm{a}$ \\
\hline imazapyr & 4,00 & $15,00 \mathrm{fg}$ & $21,67 \mathrm{efg}$ & 58,33 bcde & $80,00 \mathrm{abcd}$ \\
\hline imazapyr & 5,00 & $15,00 \mathrm{fg}$ & $18,33 \mathrm{fg}$ & $53,33 \mathrm{cdef}$ & $86,67 \mathrm{abcd}$ \\
\hline imazapyr & 6,00 & $15,00 \mathrm{fg}$ & $20,00 \mathrm{efg}$ & $53,33 \mathrm{cdef}$ & $95,00 \mathrm{abc}$ \\
\hline imazapyr & $0,10 \mathrm{~kg}$ & $10,00 \mathrm{~g}$ & $10,00 \mathrm{~g}$ & 26,67 ef & $55,00 \mathrm{bcd}$ \\
\hline imazapyr & $0,20 \mathrm{~kg}$ & $10,00 \mathrm{~g}$ & $10,00 \mathrm{~g}$ & 26,67 ef & $55,00 \mathrm{bcd}$ \\
\hline $2,4-\mathrm{D}$ & 2,00 & $50,00 \mathrm{~g}$ & $81,67 \mathrm{ab}$ & $100,00 \mathrm{a}$ & $100,00 \mathrm{a}$ \\
\hline $2,4-\mathrm{D}$ & 4,00 & $78,33 \mathrm{bc}$ & $85,00 \mathrm{a}$ & $100,00 \mathrm{a}$ & $100,00 \mathrm{a}$ \\
\hline metsulfuron & $2,00 \mathrm{~g}$ & 23,33 ef & $25,00 \mathrm{def}$ & $30,00 \mathrm{ef}$ & $40,00 \mathrm{~d}$ \\
\hline metsulfuron & $4,00 \mathrm{~g}$ & $10,00 \mathrm{~g}$ & $10,00 \mathrm{~g}$ & $15,00 \mathrm{f}$ & $53,33 \mathrm{~cd}$ \\
\hline Metsulfuron & $6,00 \mathrm{~g}$ & $10,00 \mathrm{~g}$ & $10,00 \mathrm{~g}$ & $15,00 \mathrm{f}$ & $53,33 \mathrm{~cd}$ \\
\hline sulfosate & 2,00 & $25,00 \mathrm{~g}$ & $35,00 \mathrm{de}$ & 40,00 ef & $55,00 \mathrm{~cd}$ \\
\hline sulfosate & 3,00 & $31,67 \mathrm{~g}$ & $40,00 \mathrm{f}$ & $45,00 \mathrm{def}$ & $55,00 \mathrm{~cd}$ \\
\hline testemunha & - & $00,00 \mathrm{~h}$ & $00,00 \mathrm{~h}$ & $00,00 \mathrm{~g}$ & $00,00 \mathrm{e}$ \\
\hline F tratamento & & $211,22 * *$ & $102,14 * *$ & $20,51 * *$ & $9,25 * *$ \\
\hline $\mathrm{CV}(\%)$ & & 6,44 & 8,18 & 17,05 & 15,86 \\
\hline d.m.s. & & 6,63 & 10,64 & 30,39 & 33,57 \\
\hline
\end{tabular}

${ }^{1 /}$ produto comercial; $* *$ significativo a $1 \%$ de probabilidade.

Médias acompanhadas de mesma letra não diferem estatisticamente entre si. 
Tabela 3 - Notas de avaliação do controle de E. crassipes promovido pelos herbicidas glyphosate e imazapyr aplicados em duas doses e três intervalos antes da incidência de chuva simulada

\begin{tabular}{|l|c|c|c|c|c|}
\hline \multirow{2}{*}{ Herbicida } & Dose (p.c.) & Intervalo para a & \multicolumn{3}{|c|}{ Avaliação (dias após a aplicação) } \\
\cline { 3 - 6 } & $\mathrm{L} \mathrm{ha}^{-1}$ & chuva (horas) & 10 & 20 & 30 \\
\hline glyphosate & $5 \mathrm{~kg}$ & 3 & $73,33 \mathrm{a}$ & $86,67 \mathrm{~b}$ & $96,67 \mathrm{ab}$ \\
glyphosate & $5 \mathrm{~kg}$ & 6 & $83,33 \mathrm{a}$ & $93,33 \mathrm{ab}$ & $96,67 \mathrm{ab}$ \\
glyphosate & $5 \mathrm{~kg}$ & 9 & $83,33 \mathrm{a}$ & $96,67 \mathrm{ab}$ & $98,33 \mathrm{a}$ \\
glyphosate & $6 \mathrm{~kg}$ & 3 & $80,00 \mathrm{a}$ & $95,00 \mathrm{ab}$ & $98,33 \mathrm{a}$ \\
glyphosate & $6 \mathrm{~kg}$ & 6 & $90,00 \mathrm{a}$ & $100,00 \mathrm{a}$ & $100,00 \mathrm{a}$ \\
glyphosate & $6 \mathrm{~kg}$ & 9 & $88,33 \mathrm{a}$ & $100,00 \mathrm{a}$ & $100,00 \mathrm{a}$ \\
imazapyr & 4 & 3 & $15,00 \mathrm{~b}$ & $36,67 \mathrm{c}$ & $75,00 \mathrm{c}$ \\
imazapyr & 4 & 6 & $15,00 \mathrm{~b}$ & $36,67 \mathrm{c}$ & $75,00 \mathrm{c}$ \\
imazapyr & 4 & 9 & $15,00 \mathrm{~b}$ & $36,67 \mathrm{c}$ & $73,33 \mathrm{c}$ \\
imazapyr & 6 & 3 & $15,00 \mathrm{~b}$ & $35,00 \mathrm{c}$ & $81,67 \mathrm{bc}$ \\
imazapyr & 6 & 6 & $15,00 \mathrm{~b}$ & $40,00 \mathrm{c}$ & $83,33 \mathrm{bc}$ \\
Imazapyr & 6 & 9 & $15,00 \mathrm{~b}$ & $40,00 \mathrm{c}$ & $90,00 \mathrm{abc}$ \\
testemunha & - & - & $78,00 \mathrm{c}$ & $0,00 \mathrm{~d}$ & $0,00 \mathrm{~d}$ \\
\hline F tratamento & & & 10,04 & $38,59 * *$ & $10,82 * *$ \\
CV (\%) & & & 13,14 & 11,08 & 8,63 \\
d.m.s. & & & & 19,61 & 19,04 \\
\hline
\end{tabular}

${ }^{1 /}$ produto comercial; $* *$ significativo a $1 \%$ de probabilidade.

Médias acompanhadas de mesma letra não diferem estatisticamente entre si.

No período experimental, o glyphosate promoveu maior eficácia de controle do aguapé que o imazapyr. Para o glyphosate, o controle final (30 dias após a aplicação) não sofreu influência do intervalo entre a aplicação e a ocorrência de chuva, no período e intensidade testados no presente experimento. No entanto, o desenvolvimento inicial dos sintomas foi mais rápido em intervalos maiores. As doses de 5,00 e $6,00 \mathrm{~kg} \mathrm{ha}^{-1}$ proporcionaram controle similar aos 30 dias após a aplicação, em intervalos de seis e nove horas entre a aplicação e a ocorrência de chuva. Para o imazapyr, o controle final (30 dias após a aplicação) foi maior para a dose de 6,00 L ha-1.

\section{$4^{\circ}$ experimento - Diferentes doses de diquat, aplicadas nos períodos noturno e diurno}

Encontram-se na Tabela 4 os resultados referentes ao controle de aguapé por diferentes doses de diquat aplicadas nos períodos diurno e noturno, bem como os resultados da análise de variância e do teste de comparação de médias.

Aos 20 e aos 30 dias após a aplicação, pela análise das variáveis principais (não houve significância da interação D x H), não há diferenças significativas entre os controles proporcionados pelas doses de 1,0; 2,0; e 3,0 $\mathrm{L} \mathrm{ha}^{-1}$, mas todas promoveram maior atividade biológica que a dose de $0,5 \mathrm{~L} \mathrm{ha}^{-1}$ no controle do aguapé. O controle não foi influenciado pelo horário de aplicação.

\section{5 o experimento - Diferentes doses de diquat, aplicadas nos períodos noturno e diurno e a diferentes intervalos entre a aplicação do herbicida e a incidência de chuva simulada}

Nas Tabela 5 e 6 estão apresentados os resultados referentes às avaliações de controle de aguapé proporcionado pelas doses de 1,0 e 2,0 $\mathrm{L} \mathrm{ha}^{-1}$ de diquat, aplicadas nos períodos diurno ou noturno e com aplicação de chuva simulada de $6,92 \mathrm{~mm}$ durante 10 minutos em intervalos de 30, 60 e 120 minutos.

A interação entre as dose de diquat e o horário de aplicação apenas foi significativa para a primeira avaliação. O horário de aplicação apenas influenciou o desempenho herbicida do diquat na menor dose. Para as duas doses, o horário noturno permitiu maior controle do aguapé pelo diquat. 
Tabelas 4 - Notas de avaliação do controle de E. crassipes promovido pelo herbicida diquat aplicado em diferentes doses e horários de aplicação

\begin{tabular}{|c|c|c|c|c|c|}
\hline \multirow{2}{*}{ Herbicida } & \multirow{2}{*}{$\begin{array}{c}\text { Dose (p.c.) })^{\frac{1}{\prime}} \\
\mathrm{L} \mathrm{ha}^{-1}\end{array}$} & \multirow{2}{*}{$\begin{array}{l}\text { Horário de } \\
\text { aplicação }\end{array}$} & \multicolumn{3}{|c|}{ Avaliação (dias após a aplicação) } \\
\hline & & & 10 & 20 & 30 \\
\hline diquat & 0,5 & Dia & $60,00 \mathrm{~d}$ & $80,00 \mathrm{~b}$ & $95,00 \mathrm{~b}$ \\
\hline diquat & 0,5 & Noite & $55,00 \mathrm{e}$ & $80,00 \mathrm{~b}$ & $95,00 \mathrm{~b}$ \\
\hline diquat $\mathrm{t}$ & 1,0 & Dia & $68,75 \mathrm{c}$ & $97,50 \mathrm{a}$ & $100,00 \mathrm{a}$ \\
\hline diquat & 1,0 & Noite & $100,00 \mathrm{a}$ & $100,00 \mathrm{a}$ & $100,00 \mathrm{a}$ \\
\hline diquat $\mathrm{t}$ & 2,0 & Dia & $95,00 \mathrm{~b}$ & $100,00 \mathrm{a}$ & $100,00 \mathrm{a}$ \\
\hline diquat & 2,0 & Noite & $100,00 \mathrm{a}$ & $100,00 \mathrm{a}$ & $100,00 \mathrm{a}$ \\
\hline diquat $\mathrm{t}$ & 3,0 & Dia & $100,00 \mathrm{a}$ & $100,00 \mathrm{a}$ & $100,00 \mathrm{a}$ \\
\hline diquat & 3,0 & Noite & $100,00 \mathrm{a}$ & $100,00 \mathrm{a}$ & $100,00 \mathrm{a}$ \\
\hline Testemunha & - & - & $0,00 \mathrm{f}$ & $0,00 \mathrm{c}$ & $0,00 \mathrm{c}$ \\
\hline F tratamento & - & - & $2715,38 * *$ & $55,85 * *$ & $146,07 * *$ \\
\hline Doses (D) & - & - & $3943,93 * *$ & $126,78 * *$ & $303,43 * *$ \\
\hline Horário $(\mathrm{H})$ & - & - & $1456,29 * *$ & $0,99^{\mathrm{ns}}$ & $0,01^{\mathrm{ns}}$ \\
\hline $\mathrm{D} \times \mathrm{H}$ & - & - & $863,69 * *$ & $0,98^{\mathrm{ns}}$ & $0,01^{\mathrm{ns}}$ \\
\hline $\mathrm{CV}(\%)$ & - & - & 1,08 & 3,87 & 1,09 \\
\hline
\end{tabular}

${ }^{1 /}$ produto comercial; ** significativo a $1 \%$ de probabilidade; ${ }^{\text {ns }}$ não-significativo.

Médias acompanhadas de mesma letra não diferem estatisticamente entre si.

Tabela 5 - Notas de avaliação do controle de E. crassipes promovido pelo herbicida diquat aplicado em duas doses, em diferentes horários e intervalos de tempo antes da ocorrência de chuva simulada

\begin{tabular}{|c|c|c|c|c|c|c|}
\hline \multirow{2}{*}{ Herbicida } & \multirow{2}{*}{$\begin{array}{c}\text { Dose (p.c. })^{\frac{1 /}{}} \\
\mathrm{L} \mathrm{ha}^{-1}\end{array}$} & \multirow{2}{*}{$\begin{array}{c}\text { Intervalo para } \\
\text { a chuva (minutos) }\end{array}$} & \multirow{2}{*}{$\begin{array}{l}\text { Horário da } \\
\text { aplicação }\end{array}$} & \multicolumn{3}{|c|}{ Avaliação (dias após aplicação) } \\
\hline & & & & 10 & 20 & 30 \\
\hline diquat $\mathrm{t}$ & 1,00 & 30 & Dia & 61,67 & 66,67 & 71,67 \\
\hline diquat & 1,00 & 30 & Noite & 65,00 & 66,67 & 75,00 \\
\hline diquat $\mathrm{t}$ & 1,00 & 60 & Dia & 60,00 & 63,33 & 68,33 \\
\hline diquat & 1,00 & 60 & Noite & 70,00 & 80,00 & 85,00 \\
\hline diquat $\mathrm{t}$ & 1,00 & 120 & Dia & 53,33 & 58,33 & 66,67 \\
\hline diquat & 1,00 & 120 & Noite & 75,00 & 85,00 & 90,00 \\
\hline diquat $\mathrm{t}$ & 2,00 & 30 & Dia & 71,67 & 86,67 & 90,00 \\
\hline diquat & 2,00 & 30 & Noite & 71,67 & 93,33 & 100,00 \\
\hline diquat $\mathrm{t}$ & 2,00 & 60 & Dia & 75,00 & 90,00 & 100,00 \\
\hline diquat & 2,00 & 60 & Noite & 75,00 & 96,67 & 100,00 \\
\hline diquat $\mathrm{t}$ & 2,00 & 120 & Dia & 75,00 & 83,33 & 95,00 \\
\hline diquat & 2,00 & 120 & Noite & 75,00 & 96,67 & 100,00 \\
\hline testemunha & - & - & & 0,00 & 0,00 & 0,00 \\
\hline Tratamentos & & & & $31,06 * *$ & $9,27 * *$ & $146,53 * *$ \\
\hline Dose (D) & & & & $158,76^{* *}$ & $69,40 * *$ & $1198,55 * *$ \\
\hline Intervalo (I) & & & & $2,34^{\mathrm{ns}}$ & $1,46^{\mathrm{ns}}$ & $25,04 * *$ \\
\hline Horário $(\mathrm{H})$ & & & & $50,67 * *$ & $22,00 * *$ & $231,91 * *$ \\
\hline $\mathrm{D} \times \mathrm{I}$ & & & & $2,86^{\mathrm{ns}}$ & $0,62^{\mathrm{ns}}$ & $13,49 * *$ \\
\hline $\mathrm{D} \times \mathrm{H}$ & & & & $50,66 * *$ & $0,14^{\mathrm{ns}}$ & $0,02^{\mathrm{ns}}$ \\
\hline $\mathrm{H} \times \mathrm{I}$ & & & & $17,85^{* *}$ & $2,40^{\mathrm{ns}}$ & $15,30 * *$ \\
\hline $\mathrm{CV}(\%)$ & & & & 2,38 & 9,89 & 2,76 \\
\hline
\end{tabular}

${ }^{1 /}$ produto comercial; $* *$ significativo a $1 \%$ de probabilidade; ${ }^{\text {ns }}$ não-significativo.

Médias acompanhadas de mesma letra não diferem estatisticamente entre si. 
Tabela 6 - Valores médios obtidos nos desdobramentos dos graus de liberdade dos tratamentos envolvendo doses e horários de aplicação de diquat e intervalos de tempo entre a aplicação e chuva simulada

\begin{tabular}{|c|c|c|c|}
\hline \multirow{2}{*}{$\begin{array}{c}\text { Variáveis e } \\
\text { desdobramentos }\end{array}$} & \multicolumn{3}{|c|}{ Avaliação (dias após a aplicação) } \\
\hline & 10 & 20 & 30 \\
\hline \multicolumn{4}{|c|}{ Efeitos da dose de diquat } \\
\hline $1 \mathrm{~L} \mathrm{ha}^{-1}$ & $64,17 \mathrm{~b}$ & $70,00 \mathrm{~b}$ & $76,11 \mathrm{~b}$ \\
\hline $2 \mathrm{~L} \mathrm{ha}^{-1}$ & $73,89 \mathrm{a}$ & $91,11 \mathrm{a}$ & $97,50 \mathrm{a}$ \\
\hline \multicolumn{4}{|c|}{ Efeitos do intervalo anterior à chuva } \\
\hline 30 minutos & $67,50 \mathrm{a}$ & $78,33 \mathrm{a}$ & $84,17 \mathrm{c}$ \\
\hline 60 minutos & $70,00 \mathrm{a}$ & 82,50 a & 88,33 a \\
\hline 120 minutos & 69,58 a & 80,83 a & $87,92 \mathrm{~b}$ \\
\hline \multicolumn{4}{|c|}{ Efeitos do horário de aplicação } \\
\hline Diurna & $66,11 \mathrm{~b}$ & $74,72 \mathrm{~b}$ & $81,94 \mathrm{~b}$ \\
\hline Noturna & $71,94 \mathrm{a}$ & 86,39 a & 91,67 a \\
\hline \multicolumn{4}{|c|}{ Efeitos de doses dentro do intervalo de 30 minutos antes da chuva } \\
\hline $1 \mathrm{~L} \mathrm{ha}^{-1}$ & 63,33 & 66,67 & $73,33 \mathrm{bg}$ \\
\hline $2 \mathrm{~L} \mathrm{ha}^{-1}$ & 71,67 & 90,00 & $95,00 \mathrm{ag}$ \\
\hline \multicolumn{4}{|c|}{ Efeitos de doses dentro do intervalo de 60 minutos antes da chuva } \\
\hline $1 \mathrm{~L} \mathrm{ha}^{-1}$ & 65,00 & 71,67 & $76,67 \mathrm{bgh}$ \\
\hline $2 \mathrm{~L} \mathrm{ha}^{-1}$ & 75,00 & 93,33 & 100,00 ah \\
\hline \multicolumn{4}{|c|}{ Efeitos de doses dentro do intervalo de 120 minutos antes da chuva } \\
\hline $1 \mathrm{~L} \mathrm{ha}^{-1}$ & 64,17 & 71,67 & $78,33 \mathrm{bh}$ \\
\hline $2 \mathrm{~L} \mathrm{ha}^{-1}$ & 75,00 & 90,00 & $97,50 \mathrm{ag}$ \\
\hline \multicolumn{4}{|c|}{ Efeitos do horário de aplicação dentro da dose de $1,00 \mathrm{~L} \mathrm{ha}^{-1}$} \\
\hline Diurna & $58,33 \mathrm{~b}$ & 62,78 & 68,89 \\
\hline Noturna & $70,00 \mathrm{a}$ & 77,22 & 83,33 \\
\hline \multicolumn{4}{|c|}{ Efeitos do horário de aplicação dentro da dose de $2,00 \mathrm{~L} \mathrm{ha}^{-1}$} \\
\hline Diurna & 73,89 a & 86,67 & 95,00 \\
\hline Noturna & 73,89 a & 95,56 & 100,00 \\
\hline \multicolumn{4}{|c|}{ Efeito do horário dentro do intervalo de 30 minutos para a chuva } \\
\hline Diurna & 66,67 a & 76,67 & $80,83 \mathrm{~b}$ \\
\hline Noturna & $68,33 \mathrm{a}$ & 80,00 & $87,50 \mathrm{a}$ \\
\hline \multicolumn{4}{|c|}{ Efeito do horário dentro do intervalo de 60 minutos para a chuva } \\
\hline Diurna & $67,50 \mathrm{~b}$ & 76,67 & $84,17 \mathrm{~b}$ \\
\hline Noturna & $72,50 \mathrm{a}$ & 88,33 & $92,50 \mathrm{a}$ \\
\hline \multicolumn{4}{|c|}{ Efeito do horário dentro do intervalo de 120 minutos para a chuva } \\
\hline Diurna & $64,17 \mathrm{~b}$ & 70,83 & $80,83 \mathrm{~b}$ \\
\hline Noturna & $75,00 \mathrm{a}$ & 90,83 & $95,00 \mathrm{a}$ \\
\hline
\end{tabular}

Médias acompanhadas de mesma letra não diferem estatisticamente entre si.

De maneira geral, o diquat mostrou elevada atividade herbicida contra o aguapé, sendo sua eficácia maior na dose de 2,00 L ha-1. A ação do produto também foi maior em aplicações noturnas. Neste horário de aplicação, houve maior importância da extensão do intervalo entre a aplicação do produto e a ocorrência da primeira chuva.

\section{$6^{\circ}$ experimento - Estudo de diferentes doses de imazapyr}

Na Tabela 7 encontram-se os resultados referentes às avaliações de controle de aguapé proporcionado por diferentes doses de imazapyr aos 10, 20 e 30 dias após a aplicação.

Tabela 7 - Avaliações do controle de E. crassipes promovido pelo herbicida imazapyr aplicado em diferentes doses

\begin{tabular}{|l|c|c|c|c|}
\hline \multirow{2}{*}{ Herbicida } & Dose (p.c.) (1/ $^{1 /}$ & \multicolumn{3}{|c|}{ Avaliação (dias após a aplicação) } \\
\cline { 3 - 5 } & L ha $^{-1}$ & 10 & 20 & 30 \\
\hline imazapyrr & 1,00 & $36,67 \mathrm{~b}$ & $93,33 \mathrm{~b}$ & $100,00 \mathrm{a}$ \\
imazapyr & 2,00 & $42,17 \mathrm{~b}$ & $98,00 \mathrm{a}$ & $100,00 \mathrm{a}$ \\
imazapyr & 3,00 & $49,50 \mathrm{ab}$ & $100,00 \mathrm{a}$ & $100,00 \mathrm{a}$ \\
imazapyr & 6,00 & $58,67 \mathrm{a}$ & $100,00 \mathrm{a}$ & $100,00 \mathrm{a}$ \\
imazapyr & 8,00 & $58,67 \mathrm{a}$ & $100,00 \mathrm{a}$ & $100,00 \mathrm{a}$ \\
Testemunha & - & $0,00 \mathrm{c}$ & $0,00 \mathrm{c}$ & $0,00 \mathrm{~b}$ \\
\hline F tratamento & & $8,18^{* *}$ & $27,09 * *$ & - \\
CV (\%) & & 11,04 & 5,42 & - \\
d.m.s. & & 8,34 & 7,76 & - \\
\hline
\end{tabular}

${ }^{1 /}$ produto comercial; ** significativo a $1 \%$ de probabilidade.

Médias acompanhadas de mesma letra não diferem estatisticamente entre si.

O imazapyr apresentou intensa ação herbicida contra Eichhornia crassipes, levando à mortalidade total das plantas; no entanto, sua ação é bastante lenta, demorando para que a morte total da planta ocorra.

Os resultados do presente trabalho de pesquisa mostram que os herbicidas diquat, glyphosate, imazapyr e 2,4-D foram altamente eficazes no controle de E. crassipes. Esses resultados confirmam pesquisas anteriores realizadas por Martins et al. (1999), estudando a ação do 2,4-D, e por Seddon (1981) e Shinohara (1988), utilizando glyphosate.

Os produtos apresentaram características bastante diferentes na ação herbicida. O diquat rapidamente evidencia seus sintomas, sendo uma vantagem para aplicações em dias subseqüentes, pela facilidade de identificação das plantas tratadas. Essa observação é interessante, pelo fato de que as plantas de aguapé se movimentam ao sabor dos ventos e das correntes d'água, mesclando plantas tratadas e não-tratadas, de um dia para o outro. Por outro lado, a ação rápida pode produzir grande quantidade de material passível de decomposição 
em curto espaço de tempo, podendo induzir intensa depleção dos níveis de oxigênio dissolvido na água. Aplicações noturnas do diquat proporcionaram maior atividade herbicida ao produto, pois, sem luz, o produto pode ser absorvido e distribuído na planta. Quando os raios luminosos atingem a planta, o herbicida inicia imediatamente a redução do íon bipiridilo. O intervalo entre a aplicação e a incidência de chuva também foi mais importante para aplicações no período noturno, pois o herbicida fica localizado mais superficialmente no tecido foliar, podendo ser lavado parcialmente antes que inicie sua ação. No período diurno, mesmo com chuva após algumas horas, já houve tempo para o herbicida desenvolver algum dano aos tecidos foliares.

O 2,4-D é outro produto que tem ação rápida, e as plantas tratadas podem ser reconhecidas pelos sintomas de epinastia acentuada. Apresenta a desvantagem do perigo da depleção dos níveis de oxigênio dissolvido da coluna d'água, porém em menor intensidade, uma vez que a mortalidade não é tão rápida quanto nas plantas tratadas com o diquat.

O glyphosate tem ação relativamente lenta, o que é uma vantagem em termos de depleção do oxigênio dissolvido da água, mas tem a desvantagem da possibilidade de aplicações múltiplas nas mesmas plantas em dias subseqüentes. A utilização de um marcador pode resolver o problema, mas aumenta o preço do controle. Braghin et al. (1993) mostraram não ser fácil o uso de marcadores químicos em plantas aquáticas. O glyphosate mostrou que necessita de um período sem chuva de três horas após a aplicação para que desenvolva seu potencial herbicida.
O imazapyr foi o produto de ação mais lenta, com as mesmas vantagens e desvantagens apontadas para o glyphosate, em termos de operacionalização e impacto do controle químico do aguapé.

\section{LITERATURA CITADA}

BRAGHIN, P.L. et al. Avaliação de diferentes marcadores químicos na visualização de macrofitas aquáticas tratadas. In: CONGRESSO BRASILEIRO DE PLANTAS DANINHAS, 14, 1993, Londrina. Resumos... Londrina: SBCPD, 1993. p. 243-244.

JOYLE, J. C.; SIKKA, H. C. Residual 2,4-D levels in the St. Johns River, Florida. J. Aquatic. Plant Manag., v. 15, p. 72-82, 1977.

MARTINS, D. et al. Controle químico de plantas daninhas aquáticas em condições controladas - caixa d'água. Planta Daninha, v. 17, n. 2, p. 289-296, 1999.

SEDDON, J. C. The control of aquatic weeds with the isopropylamine salt of $\mathrm{N}$ phosphomethyl glycine. In: CONFERENCE ON AQUATIC WEEDS AND THEIR CONTROL, 1981, Oxford. Proceedings... Oxford: 1981. p.141-148.

SELVAN, R. P.; LALL, M. Chemical control of water hyacinth. In: ANNUAL CONFERENCE OF INDIAN SOCIETY OF WEED SCIENCE, 1981, Anchra Prades. Abstracts... Anchra Prades: 1981. p. 34.

SHINOHARA, R. K. et al. Controle do aguapé (Eichhornia crassipes) e alface d'água (Pistia stratiotes) com a utilização do glyphosate. In: CONGRESSO BRASILEIRO DE HERBICIDAS E PLANTAS DANINHAS, 17, 1988, Piracicaba. Resumos... Piracicaba: 1988. p. 346-347.

VAN, T. K.; VANDIVER Jr., V. V.; CONANT Jr. , R.D. Effects of herbicides rate and carrier volume on glyphosate phytotoxity. J. Aquatic. Plant Manag., v. 24, n. 7, p. 66-89, 1987. 